\title{
A alquimia discursiva nos processos inquisitoriais: o cruzamento das vozes do notário e do visitador nas confissões
}

DOI: http://dx.doi.org/10.21165/el.v50i1.3064

\section{Gabriele Franco ${ }^{1}$}

\section{Resumo}

No Brasil colônia, durante a visitação da Inquisição, as confissões dos possíveis "réus" eram registradas pela comissão da visitação do Tribunal do Santo Ofício no Primeiro Livro das Reconciliações e Confissões (1591-1592), doravante LRC, e possuíam três vozes discursivas: do visitador Heitor Furtado de Mendonça, do notário Manoel Francisco e dos depoentes. O objetivo deste trabalho é apresentar uma análise das vozes do notário e do visitador no discurso reportado das confissões do LRC com a finalidade de compreender como constituíam-se e validavam uma ideologia que silenciava para incriminar. Para realizar as análises, utilizou-se como metodologia o modelo tridimensional proposto pela teoria da Análise Crítica do Discurso (FAIRCLOUGH, 2001). Para compreender o contexto jurídico, linguístico e histórico recorre-se, respectivamente, a Soares (2018), Mota (2016) e Assis (2019).

Palavras-chave: Análise Crítica do Discurso; cruzamento de vozes; inquisição; Primeiro Livro das Reconciliações e Confissões (1591-1592); discurso reportado.

1 Universidade de São Paulo (USP), São Paulo, São Paulo, Brasil; gabrielefrancousp@gmail.com; https://orcid.org/0000-0001-6580-4796 


\title{
Discursive alchemy in inquisitorial processes: the crossing of the voices of the notary and the visitor in confessions
}

\begin{abstract}
In colonial Brazil, during the visitation of the Inquisition, the confessions of possible "defendants" were recorded by the visitation commission of the Tribunal do Santo Oficio in the First Book of Reconciliations and Confessions [Primeiro Livro das Reconciliações e Confissões] (1591-1592), hereinafter LRC, and had three discursive voices: visitor Heitor Furtado de Mendonça, notary Manoel Francisco, and deponents. The objective of this work is to present an analysis of the voices of the notary and the visitor in the reported speech of the LRC confessions to understand how they constituted and validated an ideology that was silenced to incriminate. To carry out the analyzes, the three-dimensional model proposed by the Fairclough Critical Discourse Analysis theory (2001) was used as methodology. To understand the legal, linguistic and historical context, Soares (2018), Mota (2016), and Assis (2019) are used, respectively.
\end{abstract}

Keywords: Critical Discourse Analysis; crossing of voices; inquisition; First Book of Reconciliations and Confessions (1591-1592); reported speech.

\section{Introdução}

O Tribunal do Santo Ofício da Inquisição inaugurou um sistema jurídico portador de um discurso que, sistematicamente, institucionalizava a violência e sacrificava pessoas. Sua atuação viabilizou-se por apoiar-se numa sólida estrutura organizacional, envolvendo procedimentos específicos como visitações periódicas a todos os recantos do Império lusitano e uma rede de funcionários permanentes. Em 1591, uma comissão da visitação do Santo Ofício desembarcou na Bahia e mudou todo o cenário da colônia. Ela era composta por três funcionários: o visitador Heitor Furtado de Mendonça, o notário Manoel Francisco e o meirinho Francisco Gouveia.

Durante visitação do Santo Ofício ao Brasil, o notário Manoel Francisco redigiu nove livros com denúncias, confissões e reconciliações ${ }^{2}$ : quatro de denunciações, três de confissões e dois de ratificações. Dentre eles, foram selecionadas, para análise neste artigo, seis confissões registradas no Primeiro Livro das Reconciliações e Confissões (1591-1592). Tais confissões pertencem a mulheres da família Antunes, todas suspeitas do crime herético de judaísmo.

\footnotetext{
2 Destes livros, apenas quatro foram localizados e publicados. Dois relativos às denúncias e confissões da Bahia, organizadas e prefaciadas por Capistrano de Abreu entre 1922 e 1935 e outros dois também sobre denúncias e confissões em Pernambuco. A documentação produzida no período inquisitorial foi alocada na Biblioteca Pública de Lisboa e posteriormente, entre 1824 e 1836, incorporadas à Torre do Tombo (FEITLER, 2014, p. 56).
} 
Segundo Soares (2018), as demais heresias eram tratadas residualmente pelo Tribunal, mas o crime de judaísmo era considerado gravíssimo. Contudo, além da divergência religiosa, os judeus incomodavam porque sua habilidade comercial os convertia em uma burguesia em ascensão. Após desenvolverem-se economicamente, desejavam conquistar poder político, ameaçando a nobreza e o clero. Por isso, os judeus foram duramente perseguidos, processados, condenados ao confisco de bens e à morte pelos tribunais da Inquisição.

No caso das confissões das mulheres da família Antunes, podemos elaborar hipóteses sobre a possibilidade de que as depoentes foram vítimas de uma "armadilha discursiva" colocada em prática pelo notário, pelo visitador e viabilizada pela estrutura composicional (FAIRCLOUGH, 2001) do gênero confissão para justificar a perseguição, o confisco de bens e a condenação (FRANCO, 2021). Esta armadilha torna-se possível por meio do discurso reportado que recorre aos verbos dicendi para construir o cruzamento de vozes discursivas. Nesse sentido, Fairclough (2001, p. 140) afirma que: "as vozes do relator(a) e do relatado(a) são menos claramente demarcadas, e as palavras usadas para representar o discurso no último caso podem ser do(a) relator(a) e não as do relatado (a).".

Ao considerar esta hipótese, o primeiro ponto a ser explorado é a intencionalidade do Santo Ofício diante das confissões que se organizam em torno do discurso relatado e dos verbos dicendi para construir um efeito de afastamento sobre o dito e seu autor, conferindo, assim, uma aparente neutralidade. Um segundo ponto a ser considerado são os vocábulos que acompanham os verbos dicendi, pois delatam as estratégias utilizadas na seleção do léxico, bem como a identidade social, a ideologia, o contexto situacional e a busca de expressividade a fim de "convencer", "acusar" ou "condenar".

Portanto, o objetivo deste trabalho é apresentar uma análise do discurso reportado e dos verbos dicendi nas vozes do notário e do visitador em seis confissões do Primeiro Livro das Reconciliações e Confissões (1591-1592) para compreender o modo de construção e sustentação de um discurso organizado com a finalidade de silenciar e incriminar.

Além desta introdução, este artigo encontra-se organizado em quatro partes. A primeira consiste em uma breve explanação sobre a metodologia e a base teórica da Análise Crítica do Discurso (FAIRCLOUGH, 2001) utilizada para analisar as confissões. Na segunda, encontra-se a contextualização histórica da perseguição dos judeus desde a Europa até o Brasil, bem como uma contextualização do contexto de produção das confissões. As análises e os resultados dos efeitos do discurso reportado e dos verbos dicendi no cruzamento das vozes do notário e do visitador encontram-se, respectivamente, na terceira e quarta parte. 


\section{Embasamento teórico e metodologia}

Foram selecionadas seis confissões do LRC para compor o corpus: Ana Rodrigues (ANTT, 1592, $n^{\circ}$ 87, fol.142v a 145r), Beatriz Antunes (ANTT, 1592, n 84, fol.139v a 141r), Dona Leonor (ANTT, 1592, n 88, fol.145r a 147v), Custódia de Faria (ANTT, 1592, n 83, fol. 138r a 139v), Isabel Antunes (ANTT, 1592, $n^{\circ}$ 89, fol.147v a 148r) e Ana Alcoforado (ANTT, 1592, n¹21, 178r a 180r). O Primeiro Livro das Reconciliações e Confissões (1591-1592) encontra-se no Arquivo Nacional da Torre do Tombo (ANTT) e foi editado por Mota (2016). As confissões analisadas e citadas neste artigo foram modernizadas por Franco (2021) com base na edição de Mota (2016) e encontram-se no prelo.

Como metodologia e embasamento teórico para a análise das confissões, utiliza-se o modelo tridimensional de Fairclough (2001) que propõe investigar o discurso em três dimensões: prática social, prática discursiva e texto.

A análise da prática social envolveu investigação nos diferentes níveis da sociedade e no contexto histórico que precedeu a visitação do Santo Ofício à Bahia. No cerne de sua abordagem, encontram-se as questões de ideologia e hegemonia (FAIRCLOUGH, 2001), isto é, como as relações de dominação/subordinação estabelecidas pelo Santo Ofício no Brasil colônia assumiam formas econômicas, políticas e ideológicas com base na classe, no gênero social, no grupo cultural, entre outros. Como suporte teórico para compreender este contexto, recorre-se ao pesquisador e historiador Angelo Adriano Faria de Assis (2004), especialista em criptojudaísmo feminino durante a visitação do Tribunal do Santo Ofício à Bahia.

A análise do processo de produção e consumo de uma confissão engloba a dimensão discursiva (FAIRCLOUGH, 2001); para analisá-la, é importante compreender quem, como produzia e onde circulava este gênero. Neste aspecto, utiliza-se também como base teórica Soares (2018), que se dedica ao estudo do crime de judaísmo, sob o ponto de vista jurídico, e Mota (2016) que estuda o fenômeno da perspectiva linguística. Foi necessário compreender a institucionalidade das fontes inquisitoriais, bem como identidade e a mentalidade desse coletivo, representado por seus notários e inquisidores.

Para Fairclough (2001), a dimensão do texto é explorada por meio da análise textual que pode ser organizada em itens, como o vocabulário, a gramática, a coesão e a estrutura textual. A gramática indica o modo como o uso e a combinação dos verbos gera um efeito de sentido e de intencionalidade quando associados ao gênero em questão, a confissão. O efeito de sentido está associado à coesão do texto, pois a função da confissão não é dar voz aos depoentes, mas construir relatos que os incriminem. Em relação à dimensão textual, foi realizado um recorte no vocabulário e a análise encontra-se direcionada ao uso dos verbos dicendi no discurso reportado e às expressões que o qualificam ou acompanham. 


\section{O contexto de produção das confissões no Brasil colônia}

Em 1492, os Reis Fernando e Isabel da Espanha expulsaram todos os judeus do território real. Aqueles que não aceitavam o exílio eram forçosamente convertidos ao cristianismo e se deixassem a Espanha perderiam seus bens e pertences comerciais. Neste cenário, Portugal foi visto como um país de abrigo. Contudo, em 05 de dezembro de 1496, o rei de Portugal, D. Manuel, pressionado pela monarquia espanhola, exigiu a conversão forçada, sem dar-lhes o direito de emigrar. Uma migração em massa levaria grande parte do capital necessário à descoberta e exploração das colônias, ameaçando a dominação hegemônica e ideológica exercida pela igreja e monarquia.

Os judeus forçosamente convertidos e seus descendentes passaram a ser categorizados pela Igreja como "cristãos novos". Contudo, devido à conversão forçada, eles levantavam desconfianças gerais acerca de suas preferências religiosas. Assim, o cristão novo construiu uma identidade própria, pois não era completamente aceito pelos judeus, nem pelos cristãos. Alguns permaneceram secretamente praticando os costumes judaicos com a intenção de manter viva a cultura religiosa que foram obrigados a abandonar e outros mantinham as práticas judias apenas por tradições de costumes familiares. Ambos foram denominados pela historiografia como "criptojudeus".

A princípio, aqueles que vieram para o Brasil fugindo das perseguições implantadas em Portugal gozavam de certa tranquilidade. O crescimento da presença cristã nova na América portuguesa, local preferido pelos cristãos novos que escolhiam a diáspora como forma de vencer as perseguições no reino, estenderia os olhares da Inquisição sobre o Brasil, designando o Santo Ofício para monitorar a fé, o comportamento religioso nos trópicos e confiscar bens (SOARES, 2018).

Contudo, em 1591, o cenário de liberdade na colônia muda com a visitação de uma comissão do Santo Ofício que desembarca em terras brasileiras em 22 de julho de 1591. Ela estava composta por três funcionários: o visitador Heitor Furtado de Mendonça, o notário Manoel Francisco e o meirinho Francisco Gouveia.

O visitador Heitor Furtado de Mendonça era português, sem registro preciso da data de nascimento, acredita-se que no período da visitação possuía entre trinta e quarenta anos. Sua origem nobre permitiu que sua família custeasse seus estudos em um mosteiro e, assim, obteve o título de licenciado. Foi eleito como visitador do Santo Ofício em 1591. O processo de escolha para tal cargo apresentava alguns requisitos, além ser douto, era necessário comprovar "limpeza de sangue"; os antecedentes da família eram vasculhados para averiguar se havia mistura de sangue com judeus ou mouros na genealogia. Vale destacar que o reconhecimento como membro do Santo Ofício conferia prestígio social e sua função estava mais relacionada às práticas jurídicas do que religiosa. 
Segundo Vainfas (2014 apud MOTA, 2016), Heitor Furtado chegou doente à colônia e começou tardiamente o trabalho. Por isso, fez o que lhe pareceu conveniente ou razoável: o visitador abandonou as instruções do Conselho Geral e foi subjetivo em suas acusações. Talvez por este comportamento, foi solicitado seu retorno à Lisboa antes de visitar as capitanias do Sul e as ilhas do Atlântico.

O notário Manoel de Francisco era padre, de origem portuguesa. Embora os notários eclesiásticos ainda existam, a profissão equivaleria à de tabelião. Sua função era registrar os depoimentos. Os requisitos para esta função eram: ser clérigo - Manoel era padre e dominar a escrita; comprovar pureza de sangue; conhecer o funcionamento do Santo Ofício; ser fiel na redação dos depoimentos; não dialogar com os depoentes e não se ausentar durante o processo.

O meirinho Francisco Gouveia era responsável por efetuar as prisões; para sua função, não era necessário possuir formação religiosa ou jurídica. Ele não possui voz nas confissões, mas não é possível afırmar até que ponto sua presença no local da confissão poderia alterar o que era dito.

Após desembarcar em terras brasileiras, a comissão do Santo Ofício foi apresentada à população em cerimônia de Auto de Fé, realizada na Câmara da cidade de Salvador. Estavam presentes pessoas de fórum nobre, como juízes, vereadores, outros oficiais e autoridades que assinaram um documento legitimando a visitação.

O cerimonial ritualístico para a apresentação da comissão era uma festividade com sermão, procissão e solenidades previamenteestabelecidas nos Regimentos da Inquisição (MOTA, 2016). Após o sermão, eram publicados os Éditos de Fé e de Graça, também denominados "tempo da graça", no qual se estabelecia um período de aproximadamente trinta dias para aqueles que desejassem confessar seus pecados. Foi neste período que todas as mulheres da família Antunes foram confessar.

A família Antunes possuía muitos bens na Bahia, inclusive um engenho governado por Ana Rodrigues, após o falecimento de seu marido Heitor Antunes. Ela assume não só a liderança da família, mas também das atividades criptojudias, visto que há registros que o engenho abrigava uma sinagoga. Não é possível delimitar com exatidão se suas filhas - Beatriz Antunes e Dona Leonor - e netas - Isabel Antunes, Custódia de Faria e Ana Alcoforado - praticavam o judaísmo de forma consciente ou apenas seguiam os costumes familiares por tradição, sem saber o real significado. Contudo, no caso de Ana Rodrigues, é possível averiguar que ela não só era consciente dos significados de suas práticas, como também se tornou uma líder (ASSIS, 2013). 
As confissões eram registradas pela comissão da visitação do Santo Ofício. Segundo Mota (2016, p. 113), a documentação produzida pela Inquisição no "tempo da graça" foi legitimada pela comissão da visitação e pelos Regimentos e manuais elaborados. Ela representa um conjunto de testemunhos que foram previamente planejados com o objetivo específico de registrar a atuação do Tribunal do Santo Ofício, descrever a confissão dos depoentes, bem como as denúncias que surgiam.

O Santo Ofício fez parte de uma tradição jurídica de origens remotas que nasce na época medieval, início do século XIII, com o IV Concílio de Latrão. O Tribunal era guiado por Regimentos e manuais com a finalidade de definir uma fórmula processual e encontrar uma verdade juridicamente válida para suas sentenças. Os inquisidores comportavamse como portadores da verdade absoluta, detinham o monopólio de salvação das almas. Segundo Feitler (2014), a Inquisição dispunha de um funcionamento incoerente e repleto de discordâncias internas que possuía a finalidade de sustentar o discurso ideológico que contribuía para a construção da verdade que se procurava impor, bem como uma justificativa legal para as atrocidades cometidas.

No Santo Ofício, buscava-se a sujeição do acusado - ao Tribunal, à Igreja e ao Monarca - pela via da confissão, arrependimento e pedido de perdão, para que fosse viável a sua reintegração social. Os testemunhos geravam medo, por isso a população, temerosa dos métodos do Santo Ofício, preferia antecipar-se a uma acusação e recorria à Mesa da Visitação para confessar e denunciar.

Segundo Soares (2018), no processo inquisitório, o réu precisava confessar algo mesmo que não tivesse "pecado". Aqueles que negassem as culpas poderiam ser submetidos à tortura e condenados à fogueira. Tamanha era a importância do falar perante a mesa inquisitorial que o Manual da Inquisição (EYMERICO, 2009 [1525]) ensinava a extrair a confissão dos processados. O juiz deveria interrogar para obter a confissão verbal, muito mais do que para obter provas. Portanto, a produção e o consumo das confissões eram exercidos pela comissão de visitação do Tribunal do Santo Ofício e os documentos serviam como aparato de repressão e registro.

\section{O notário: um alquimista do discurso}

O poder do notário está no discurso reportado, pois ele testemunha a fala da terceira pessoa de forma que o sujeito comunicante e o sujeito interpretante possam estar apagados ou desvinculados.

Considerando que a confissão como documento institucional tinha um modelo normatizado, a voz do notário torna-se metadiscursiva e permeia toda a estrutura do gênero. 
Há intencionalidade em todas as vozes, mas esse processo é mais obscuro em relação ao notário, pois ele era o responsável por traduzir toda a realidade que acontecia durante as sessões de confissão; era um alquimista que transmuta um elemento em outro, isto é, o discurso direto em indireto.

Nas confissões, o registro do discurso reportado surge quando toma forma de uma oração gramaticalmente subordinada à oração que relata, uma conjunção marcada pela conjunção "que". O período "Confessando-se disse que faziam vinte e nove ou trinta anos que estava casada" (FRANCO, 2021, no prelo) possui quatro orações: "(1) Confessando-se/ (2) disse/ (3) que faziam vinte ou trinte anos/ (4) que estava casada". A primeira oração é coordenada assindética, composta por um verbo no gerúndio com ênclise. A segunda oração é a principal e a terceira oração encontra-se subordinada a ela, pois é subordinada substantiva objetiva direta. A quarta oração encontra-se subordinada à terceira. A análise sintática do trecho citado comprova que há um discurso reportado, isto é, o enunciador toma por objeto um outro ato de enunciação.

Segundo Feitler (2014), a razão para a presença do discurso indireto nos documentos inquisitoriais deve-se à necessidade de moldá-lo a um discurso jurídico com a finalidade prática de ser útil e acessível aos juízes no momento de determinar sentenças ou compará-lo com outros documentos:

Tratava-se de moldá-lo a um discurso jurídico que fosse útil aos juízes na hora de se lavrar uma sentença ou na hora de comparar o que havia sido dito por uma testemunha com os dizeres de outra. Estas são, me parece, as verdadeiras razões do discurso indireto que lemos nos processos inquisitoriais. (FEITLER, 2014, p. 61).

Feitler (2014) ainda ressalta que o texto final era lido ao declarante no encerramento da sessão e era possível fazer reparos à construção notorial "caso os nervos deixassem".

Contudo, parte-se da hipótese de que, além da mera função prática e jurídica do discurso indireto, é possível considerar ainda uma função discursiva estratégica para simular a imparcialidade. Assim, mesmo que o discurso fosse praticamente reelaborado, era de responsabilidade do declarante. O objetivo do notário era reportá-los com coesão e coerência. Para garantir tais elementos, simulava as verdadeiras intenções do Tribunal, mesclando em sua voz o discurso das depoentes e do visitador. Dessa forma, há um limite pouco marcado entre a "voz" da pessoa que é relatada e a "voz" de quem relata.

Embora as vozes não se manifestem claramente na estrutura textual, a análise revela o cruzamento ou transição entre elas por meio dos verbos dicendi. Um exemplo de verbo dicendi como marcador do cruzamento das vozes encontra-se em: 
Perguntada quanto tempo havia que ela começou a ensinar as ditas suas filhas que fossem judias e cressem na Lei de Moisés, respondeu que: ela nunca ensinou suas filhas a serem judias, nem a lei de Moisés, nem ela nunca teve essa lei. (FRANCO, 2021, grifo nosso).

O verbo "perguntada" marca o início da voz do visitador. O verbo "respondeu" marca a voz da depoente. Assim, revelam-se com exatidão o momento de troca de perspectiva entre visitador e depoente.

Portanto, o discurso indireto é responsável por criar um simulacro de realidade, uma falsa busca por justiça que mescla autoritarismo com fé. Este efeito só se torna possível devido ao uso do discurso reportado que gera o efeito de cruzamento entre as vozes do visitador e do notário, isto é, o limite entre a voz de um ou outro torna-se tênue. Gramaticalmente, este efeito é rastreável por meio do uso dos verbos dicendi e seus complementos.

\section{Os verbos dicendi: matéria-prima do alquimista}

Nas confissões, os verbos dicendiapresentam três funções: metalinguística, argumentativa e coesiva (RODRIGUES, 2008). A função metalinguística ocorre uma vez que o narrador, ao reportar as falas, centraliza sua atenção no próprio texto, tentando caracterizá-lo ou descrevê-lo. A função argumentativa está relacionada à interpretação subjetiva que o narrador faz sobre o dito e o que deseja imprimir no texto final como verdadeiro. A função coesiva é responsável pela estruturação do texto, pois alguns verbos dão progressão e outros encerram.

Os verbos podem estar acompanhados de complementos como advérbios, substantivos e adjetivos que também caracterizam e, assim, revelam a estratégia e as possibilidades discursivas de cada um dos envolvidos na confissão. No trecho retirado da confissão de Ana Rodrigues, é possível observar o uso dos verbos e seus complementos:

Perguntada quanto tempo havia que ela começou a ensinar as ditas suas filhas que fossem judias e cressem na Lei de Moisés, respondeu que: ela nunca ensinou suas filhas a serem judias, nem a lei de Moisés, nem ela nunca teve essa lei. Foi admoestada pelo Senhor Visitador com muita caridade que ela use de bom conselho este tempo de graça, que para ela alcançar-lhe é necessário fazer confissão inteira e verdadeira nesta mesa e confessar a sua intenção judaica e que confessando ela a sua intenção e toda a verdade interior aproveitar-lheia muito para alcançar o perdão, respondeu que: ela tem dita a verdade e que nunca fez as ditas coisas com ruim intenção, nem com coração de judia, nem de ofender a Deus e nunca cuidou que as ditas coisas ofendiam [...] Contudo, ela, confessante, disse e afirmou que nunca fez as ditas coisas com intenção ruim de judia, nem de ofensa a Jesus Cristo, mas que as fez por ignorância como tem dito 
e não come cação, nem raja fresco porque the faz mal e quando punha a mão na cabeça dos netos era por fatalidade e que de toda a culpa que tem em fazer as ditas coisas exteriores, sem ter a dita intenção ruim interior como dito tem, pede perdão e misericórdia neste tempo da graça e promete segredo pelo juramento que recebeu. Por não saber assinar eu, Notário, a seu rogo, assinei com o Senhor Visitador. Manoel Francisco, Notário do Santo Ofício nesta visitação o escreve. (FRANCO, 2021, grifo nosso).

Nas confissões analisadas ${ }^{3}$, bem como no trecho citado, os verbos, seus complementos e as vozes organizam-se da seguinte forma

1. Visitador: pergunta, admoesta (com muita caridade), manda.

2. Notário: assina (ao rogo da depoente), escreve.

3. Depoente: responde, recebe (juramento), comparece (sem ser chamada), promete dizer (em tudo a verdade/ segredo), diz, confessa, afirma, faz, pede (perdão e misericórdia).

No caso do visitador, os verbos, em sua maioria, possuem função argumentativa, pois delatam a hierarquia e a autoridade representadas por ele, mas, em contrapartida, os adjetivos utilizados nas fórmulas religiosas funcionam como uma tentativa de atenuar essa sensação de autoritarismo. No momento em que o discurso do visitador é relatado e sua voz ganha espaço nas confissões, há, inicialmente, uma sessão de perguntas dirigidas às depoentes, portanto, o notário utiliza o verbo "perguntar" e, posteriormente, finaliza sua participação na confissão com o verbo "admoestar".

O verbo "perguntar" apresenta um significado com carga semântica mais neutra quando comparado ao verbo "admoestar". A escolha dos verbos e a ordem em que são alocados na frase dizem muito sobre a intenção do notário, e consequentemente, do Santo Ofício, em relação à construção do sentido dos discursos. No Dicionário Online de Português ${ }^{4}$, os significados atribuídos ao verbo "perguntar" possuem carga semântica direcionada à investigação, argumentação, resolução de problemas e, apenas em último plano, possui a função de interrogar: "indagar; questionar através de perguntas, questões; pedir; propor

3 Foi selecionado o trecho de uma confissão como exemplo, porém esta estrutura de perguntas e respostas repete-se em todas as confissões das Antunes, bem como os verbos dicendi e seus complementos. Trata-se de uma estrutura composicional fixa do gênero confissão que se encontra detalhada em Mota (2016).

4 Disponível em: https://www.dicio.com.br/perguntar/. Acesso em: 19 fev. 2020. 
uma solicitação; fazer um pedido; questionar; realizar questões; buscar esclarecimentos; investigar; procurar uma solução; interrogar. Dentre os sinônimos do verbo, encontram-se os vocábulos: pedir, demandar, inquirir, interrogar, solicitar, indagar, investigar e questionar.

O verbo "admoestar" s" significa "censurar alguém a partir da observação de seu comportamento, sua maneira de pensar ou por uma falha cometida por esta pessoa; repreender; aconselhar alguém quanto à sua maneira de proceder, para que a corrija de alguma forma; advertir, avisar, prevenir; incitar uma pessoa para que esta se comporte de acordo com o que pode ser considerado apropriado; exortar.

Isso significa que as perguntas iniciais do texto de confissão apresentam nuances mais brandas, aparentemente buscam apenas informações acerca das possíveis heresias cometidas pelas depoentes. Contudo, o uso do verbo "admoestar" revela de forma mais brusca a autoridade e possui carga semântica relacionada a uma sentença final, uma acusação.

No entanto, esta sensação de mudança repentina de tom é amenizada pelos adjetivos e orações que compõem a fórmula religiosa que engloba este verbo. O verbo "admoestar", por exemplo, está acompanhado da combinação de preposição, advérbio de intensidade e adjetivo "com muita caridade". Essa afirmação altera o sentido da coerência do texto ao revelar incongruências e contradições de um discurso que teria por finalidade descrever os fatos, tornar-se um discurso de ameaça e intimidação. Além disso, encontra-se dentro da fórmula religiosa um conjunto de orações que corroboram a atenuação da autoridade, construindo a falsa ideia de que a confissão pode ajudar a depoente a alcançar o perdão:

Foi admoestada pelo Senhor Visitador com muita caridade que ela use de bom conselho este tempo de graça, que para ela alcançar-lhe é necessário fazer confissão inteira e verdadeira nesta mesa e confessar a sua intenção judaica e que confessando ela a sua intenção e toda a verdade interior aproveitar-lhe-ia muito para alcançar o perdão [...] (FRANCO, 2021).

Portanto, os verbos dicendi que o notário escolhe para retratar o discurso do visitador estão, em um primeiro momento, relacionados à argumentação e não ao autoritarismo. Tal escolha reflete o que historiadores já afirmavam sobre a postura do Santo Ofício nas sessões de confissão: os depoentes já estavam condenados pela Inquisição, cabia ao visitador e ao notário construir as provas para legitimar e legalizar os procedimentos que transformariam as depoentes em réus nos processos.

5 Disponível em: https://www.dicio.com.br/admoestar/. Acesso em: 19 fev. 2020. 
Para Mota (2016, p. 102), Heitor Furtado possuía poder de persuasão, pois "durante as confissões, conduzia o depoente a narrar e aprofundar os fatos de interesse para a mesa inquisitorial". No entanto, as análises baseadas na perspectiva da Análise Crítica do Discurso (FAIRCLOUGH, 2001) revelam que a habilidade e o poder de persuasão do visitador devem-se apenas ao poder institucional que representava em uma relação ideológica e assimétrica de poder, diante de pessoas que se encontravam em situação de fragilidade e humilhação. Além disso, o uso que fazia da confissão, como gênero discursivo, era injusto, pois a utilizava para que o depoente narrasse e aprofundasse os fatos que o interessavam.

\section{Conclusão}

O uso do discurso reportado que rege os registros inquisitoriais isenta de culpas seus redatores, pois constrói o efeito de cruzamento de vozes e torna confuso o limite entre o dito pelo visitador e o redigido pelo notário. Assim, a confissão como gênero discursivo não atua como um agente de justiça, mas de autoridade e repressão.

Portanto, a função do Tribunal do Santo Ofício era manter o catolicismo como a única ideologia possível de compreensão do mundo. Contudo, se fossem apenas temidos, não conseguiriam manter as pessoas sobre o jugo da Igreja. Por isso, era necessário realizar um julgamento, como sinônimo de justiça e permitir aos "criminosos" o "direito" à confissão, como sinônimo de "misericórdia", visto que, durante as sessões, as rés eram constantemente advertidas a "confessar as culpas para obter misericórdia".

Tratava-se de um Tribunal da consciência, mas a igreja não aceitava a liberdade de consciência, considerada heresia máxima e, por isso, precisava controlar os indivíduos. A ameaça disfarçada de misericórdia (SOARES, 2018) só poderia ser validada e devidamente registrada por meio de uma confissão que, na composição de suas escolhas vocabulares e gramaticais, sustentava a falsa ideia de neutralidade, justiça e misericórdia.

\section{REFERÊNCIAS}

ARQUIVO NACIONAL DA TORRE DO TOMBO (ANTT). Primeiro livro de Reconciliações e Confissões. Disponível em: https://archive.org/stream/primeiravisita00sociuoft\#page/ n31/mode/2up. Acesso em: 21 nov. 2019.

ASSIS, A. A. F. de. Inquisição e judaísmo feminino na Bahia - séculos XVI-XVII. In: SILVA, M. A. N. da (org.). Estudos Inquisitoriais: história e historiografia. Cruz das Almas: UFRB, 2019 .

EYMERICO, N. Manual da Inquisição. Tradução Affonso Celso Godoy. Curitiba: Juruá, 2009 [1525]. 
FAIRCLOUGH, N. Discurso e mudança social. Tradução Izabel Magalhães. Brasília: Editora Universidade de Brasília, 2001.

FRANCO, G. Representação de vozes femininas judias na América Portuguesa. 2021. Tese (Doutorado em Filologia e Língua Portuguesa) - Faculdade de Filosofia, Letras e Ciências Humanas, Universidade de São Paulo, São Paulo, 2021 (no prelo).

FEITLER, B. Processos e práxis inquisitoriais. Revista de fontes, v. 1, n. 1, p. 55-64, 23 nov. 2014. Disponível em: https://periodicos.unifesp.br/index.php/fontes/article/view/9184. Acesso em: 13 nov. 2019.

MOTA, A. C. de A. A. Confessar em segredo: edição e estudo de um Livro de Confissões quinhentista (Inquisição de Lisboa, Liv. 777, Salvador, Bahia, 1591-1592). 2016. Tese (Doutorado em Letras) - Faculdade de Filosofia, Letras e Ciências Humanas, Universidade de São Paulo, São Paulo, 2016.

NOVINSKY, A. Os judeus que construíram o Brasil: fontes inéditas para uma nova visão da história. São Paulo: Planeta do Brasil, 2015.

DICIO, Dicionário Online de Português. Porto: 7Graus, 2020. Disponível em: https://www. dicio.com.br/risco. Acesso em: 19 fev. 2020.

RODRIGUES, T. M. B. Funções linguísticas dos verbos dicendi. In: I SIMELP, 2009, São Paulo. Simpósio Mundial de Estudos de Língua Portuguesa. São Paulo, 2008. v. 1.

SOARES, E. F. Mulher, judaísmo e inquisição nas Minas. Belo Horizonte: Editora D’Plácido, 2018.

SOUSA, M. C. P.; MONTE, V. M. (org.). M.A.P. (Mulheres na América Portuguesa): mapeamento de escritos de mulheres e sobre mulheres no espaço atlântico português a partir de métodos das Humanidades Digitais. Projeto de pesquisa. São Paulo: MCTIC/CNPq, 2018. Disponível em: http://www.nehilp.org/ nehilp/HD/MAP/. Acesso em: 01 jun. 2019.

VAINFAS, R. Trópicos dos pecados: moral, sexualidade e inquisição no Brasil. 2 ed. Rio de Janeiro: Civilização brasileira, 2014. 